\title{
Emergency Contraceptives for the Prevention of Unwanted Pregnancy among the Youth in Tamale - Perspective of the Clergy
}

\author{
Abdul-malik, abdulai ${ }^{*}$, Paul Armah Aryee ${ }^{2}$ \\ ${ }^{I}$ Nurses and Midwives Training College, Tamale, Ghana \\ ${ }^{2}$ Leturer, University for Development Studies, Tamale, Ghana
}

\begin{abstract}
Adolescent females are prone to unintended pregnancies due to the sporadic and impromptu sexual intercourse. Under such circumstances, they are unable to negotiate for safer sex. Emergency contraceptives is vital in the prevention of unintended pregnancies in such situations, but religious communities are perceived to resist modern contrasceptive. This study sought to assess the perspective of the Islamic clergy on the use EC for the prevention of pregnancy among young the people in the Tamale metropolis of the Northern Region of Ghana. A qualitative cross-sectional approach was used for this study. An in-depth interview was conducted involving a total of three clerics, one from each religious sect of the study area to assess their knowledge of EC and perspective on its use among the youth. 2 out of the 3 clerics demonstrated good knowledge of EC, including situations in which it is used and the correct time for use. They were unanimous in the use of family planning methods for birth control but indicated that it is the sole preserve of the married. They contended that the hormonal forms including EC are forbidden in Islam but in situations of forced sex; they had no objection to its use. Overall EC knowledge and awareness level among the clerics was high but strongly opposed the use of it for pregnancy prevention in general but raised no objection to its use in situations of forced sex or incest since they opined it is no fault of the victim under such circumstances.
\end{abstract}

Keywords: cleric, Emergency contraceptive, religion, unintended pregnancy.

\section{Introduction}

Unplanned or unintended pregnancy especially in adolescents constitute an important health problem worldwide and has been associated with a great number of negative health outcomes [1]. Adolescent females are more prone to unintended pregnancies because they have no stable sexual relations and therefore are unlikely to be on regular contraceptives. The unstable nature of their relationships makes sexual intercourse sporadic and impromptu, and under such circumstances they are unable to negotiate for safer sex, which may result in unintended pregnancy. The prevalence of unplanned pregnancy in adolescents worldwide ranges from $33 \%$ to 82 [2]. Approximately 16 million girls within 15 to 19 years' age bracket give birth each year in developing regions and every year, some 3.9 million adolescents aged 15 to 19 years undergo unsafe abortions as a result of unintended pregnancy [3]. In Africa, close to one-fifth of adolescents become pregnant yearly [4]. In Ghana the rate of unintended pregnancies among the age group 15-19 years stands at 69\% [5] and 30\% of all births registered in 2014 came from adolescents [6]. Socio-cultural and religious norms restrict sexual intercourse to only the married people [7] thus excluding the young unmarried people who are sexually active and also vulnerable and subject to sexual abuse or exploitations from conversation involving sex and pregnancy prevention. This practice limits their access to information on issues related to sexuality and contraception. Even if adolescents need information on sexuality and contraception, because of the cultural norms, they feel embarrassed going to parents, teachers and health facilities for information or services pertaining to sex and contraception [8]. Several studies have established a positive correlation between contraceptive knowledge and utilization and educational attainment $[9,10$, 11]. The northern region unfortunately has the 
lowest female literacy rate in Ghana and the teenage girls are usually sexually abused in schools and at home by their peers or older adults and the victims are blamed rather than the perpetrators. Majority of the teenage pregnancies arise from peer-to-peer relationships or abuse such as defilement by school teachers, and some of these girls die from complications in childbirth because their bodies are not developed enough to cope with the birthing process [12].

Because pregnancy is not the desired outcome in such instances, emergency contraception remains the only option to prevent pregnancy but its usage depends on the knowledge and the socio-cultural acceptability. Tamale is predominantly a Muslim community where the debate and criticism of FP among the religious scholars is ever going on. Many of the Islamic scholars are perceived to have an unfavorable attitude towards modern contraceptives, and this will serve as a major barrier to utilization since the cleric's views are sacrosanct.

For the young adolescent female to benefit from EC and avoid unplanned pregnancies, the product must be well known and accepted socio-culturally.

\section{Methods}

Tamale is the capital town of the Northern Region, one of the sixteen regional capitals in the country. It is located within the Guinea Savannah belt. The population of Tamale Metropolis, according to the 2010 Population and Housing Census, is 233,252 representing 9.4 percent of the region's population. Males constitute $49.7 \%$ and females represent $50.3 \%$. The proportion of the population living in urban localities $(80.8 \%)$ is higher than that living in rural localities $(19.1 \%)$ of the metropolis. The population of the metropolis is youthful (almost $36.4 \%$ of the population is below 15 years) depicting a broad-based population pyramid which tapers off with a small number of elderly persons (60 years and older) representing 5.1 percent.

A qualitative cross-sectional approach was used for this study. An in-depth interview was conducted involving a total of three clerics, to assess their knowledge on EC and perspective on its use among the youth.
A discussion guide with open-ended questions was used to probe further in seeking information that would facilitate improvement in the discussions and findings of the study. Discussions were recorded with a tape and field notes taken alongside to help capture the total views and contributions of each participant. They were asked specific questions about the position of their sect on the use of EC and other family planning products as per their religious faith, and follower's usage of contraceptives and family planning.

\section{Results}

The respondents were aged between 45 and 62 years and all were males. They were Imams or Sheiks; Arabic Instructors and others were Lecturers who were Islamic scholars at the university. 2 out of 3 clerics had good knowledge of EC including instances in which it is indicated and the right time for taking it.

All the clerics unanimously agreed that Sharia is not against family planning. They, however, indicated that Sharia does not permit the use of hormonal methods such as contraceptives pills/tablets, including EC and injectables. The reasons had been that these methods disturb the hormones in the woman and can cause some challenges in her menstrual cycle as well as health challenges. They also believe that at some point in the future the pills can stop the woman from giving birth again and so the use of such methods is not permissible.

The permission to use non-hormonal forms of contraceptive, was, however, restricted to only married adults and the cleric unanimously kicked against encouraging the Muslim youth to use FP including EC since they were of the view that Islam does not support the use of family planning among the unmarried. However, in instances of forced sex or incest, the clerics raised no objection to the use of EC since they contend it is no fault of the victim under such circumstances and also pregnancy is not the desired outcome.

\section{Discussion}

The influence of religion is pervasive in all aspects of an individual's life, including personal matters such as managing family size [13]. There are misconceptions about the permissibility of family planning in Islam and this has led to divided opinions on the part of 
the clerics on the use of modern family planning methods including EC. Religious leaders are held in high esteem in society and their views are usually sacrosanct. For this reason, their position on modern contraceptives heavily influences the uptake and utilization of these methods in the communities or societies they superintend. The Pakistan National Institute of Population Studies reported that women in communities where Ulema (Muslim religious leaders) approve the use of contraception methods were more likely to use them than women in communities where the Ulema disapproves of its use [14].

The Islamic Clerics in this study demonstrated good knowledge and understanding of FP, including EC, perhaps indicative of their sound education and experiences from elsewhere. This is similar to findings made by [15] in Asia, where Clerics reported a relatively more increased knowledge of EC.

The views of the clerics, who were the respondents on FP and EC use in this study, were clearly positive, and almost all of them agreed on how FP has been made possible by Allah. They, however, disagreed with the use of hormonal contraceptives because of the perceived interference with the female hormonal system. These views, however, contradicts those expressed by Muslim scholars in the study by [16]. According to them, with the exception of methods that leads to permanent deactivation of a reproductive organ (e.g., vasectomy and tubal ligation), which is inconsistent with Islamic teachings, any other form or method of contraception which doesn't alter the physical structure of the reproductive organ is permitted, and this includes hormonal forms. Muslim clerics in the study by [17], however, held a contrary view to the permissibility of family planning method in Islam. They opined that the prophet Muhammed entreated Muslims to multiply (that is to give birth to many children) in order to make him proud on the Day of Judgment and therefore reject FP because it will not serve the purpose of multiplication. Giving birth to many children, however, does not necessarily mean giving birth without limit, which is what FP is about. In Islam, FP is called "Tanzimulnasil" meaning "family arrangement". For those clerics who support family planning, they aver that 'family arrangement' means having a number that can be managed, which entails not just limiting births but also spacing the births as well, which brings to the fore family planning methods. They were unanimous in their view that FP was vital, and that was why Sharia permitted it, so that Muslims can plan their families, and use FP to space their children to avoid giving birth to many children which they cannot take care of on the forms of contraceptives, the Clerics did not agree to the use of the hormonal forms, which according to them, had side effects, such as interfering with the hormonal system of the woman with dire consequences. For this reason, Sharia forbids the use of these forms of contraceptives and this may influence negatively, the uptake and utilization of these forms of family planning methods including the use of EC. Similar reasons have been cited as barriers to the uptake and utilization of FP generally, among the Muslim communities in [18].

The right to FP, according to the secular laws of Ghana, means no one should be denied access and use of FP, including EC on religious grounds. The Muslim Clerics, however, were of the view that FP as a right is not universal or absolute. They restricted this right to only married couple despite the fact that unmarried young females are sexually active and would need modern family planning methods including EC. They were of the opinion that young unmarried Muslims would be encouraged to have sexual intercourse instead of abstaining if this right is extended to them.

When the question of pregnancy prevention in situations of rape or forced sex and incest using EC was posed to them, they all agreed to the use of EC since in their opinion, it will prevent having unwanted or bastard children. They averred that such situations arise not by deliberate or willful actions of the victim, and thus she cannot be made to suffer the consequences if she is not ready to do so.

Interestingly, the clerics unanimously agreed that society should be controlled by its religious beliefs which means that a predominantly Muslim society should live according to the tenets of the Islamic religion. They opined that sex education from parents is permissible and necessary in the socio-cultural context, to enable their wards take the right decisions to prevent unwanted and early pregnancy. 


\section{Conclusion and Recommendations}

According to the cleric, Sharia is not against FP; however, this right is solely the preserve of the married. They said "Sharia" permits the planning of families but were against the use of contraceptive forms that may affect the hormonal system of the woman including EC but will not object to the use of EC in pregnancy prevention in situations of rape/forced sex.

\section{References}

[1] Mohammed, F., Musa, A. and Amano, A. (2016) 'Prevalence and determinants of unintended pregnancy among pregnant woman attending ANC at Gelemso General Hospital, Oromiya Region, East Ethiopia: BMC Women's Health. 16(1), pp. 10-16.

[2] Vázquez-Nava, F. et al. (2014) 'Unplanned pregnancy in adolescents: Association with family structure, employed mother, and female friends with health-risk habits and behaviors', Journal of Urban Health, 91(1), pp. 176-185. doi: 10.1007/s11524013-9819.

[3] WHO (2018) Emergency contraception. Available at: http://www.who.int/en/newsroom/factsheets/detail/emergency-contraception

(Accessed: 19 May 2018).

[4] Kassa, G.M., Arowojolu, A.O., Odukogbe, A.A. et al. Prevalence and determinants of adolescent pregnancy in Africa: a systematic review and Metaanalysis. Reprod Health 15, 195 (2018). https://doi.org/10.1186/s12978-018-0640-2.

[5] Ameyaw, E.K. Prevalence and correlates of unintended pregnancy in Ghana: Analysis of 2014 Ghana Demographic and Health Survey. matern health, neonatol and perinatol 4, 17 (2018). https://doi.org/10.1186/s40748-018-0085-1.

[6] Coughlin J (2016): Teenage pregnancy in Ghana: Assessing situation and moving forward. www.graphic.com.gh/news/general-news/teenage pregnancy in ghana assessing situation and moving forward.html.

[7] Awusabo-Asare K, Biddlecom A, KumiKyereme A, Patterson K. (2006). Adolescent Sexual and Reproductive Health in Ghana: Results from the 2004 National Survey of Adolescents. Occasional Report No 22. New York, NY: Guttmacher Institute. [8] Rodriguez-Vignoli J. Adolescent fertility in Latin America and the Caribbean. nIUSSP [Internet]. 2017; May. Available from: http://www.niussp.org/article/adolescent fertility in
Since Ghana is a secular and not a religious state, it is recommended that health education should be extended to the Islamic scholars to help change some of their beliefs and perceptions regarding emergency contraception and other family planning methods in order for their followers to benefits greatly from family planning interventions.

latin America andthe-caribbeanla-feconditedesadolescentes-en-amerique-latine-et-dans-lesantilles.

[9] Amalba, A., Mogre, V., Appiah, M.N.A., and Mumuni, W.A., (2014) "Awareness, use and associated factors of emergency contraceptive pills among women of reproductive age (15-49 years) in Tamale, Ghana," BMC Women's Health, vol.14(114).

[10] Ezebialu I., \& Eke A., (2013). "Knowledge and practice of emergency contraception among female undergraduates in South Eastern Nigeria," Annals of Medical and Health Sciences Research, vol.3, no.4, pp.541-545,2013.

[11] Tilahun. D. F. Assefa. T., \& Belachew. T., (2010). Predictors of emergency contraceptive use among regular female students at Adama University, Central Ethiopia Pan Africa Medical Journal ISSN: 1937- 8688.

[12] GoG (2014): Child Protection baseline research, Northern regional profile, GOG, Department of children (Ministry of Gender and Social Protection, 2014] www.unicef.org.

[13] Mir A. M and Shaikha G. R (2013). Islam and family planning: changing perceptions of health care providers and medical faculty in Pakistan. Global Health: Science and Practice 1(2):228-236, DOI: 10.9745/GHSP-D-13-00019.

[14] Raza H, Sheraz A, Zafar R, Khan N, Ali H (2012). Effect of Islamic perception on family planning practices. OIDA Int J Sust Dev ;5(3):8596.

[15]Duze, M. and Mohammed, I. (2006). Male Knowledge, Attitudes, and Family Planning Practices in Northern Nigeria. African Journal of Reproductive Health, 10(3): 53-65.

[16] Yusuf B. J. (2014): Contraception and Sexual and Reproductive Awareness Among Ghanaian Muslim Youth: Issues, Challenges, and Prospects for Positive Development. 
[17] Al-Ghazali, A. H. M. (1939). Ihya' 'ulum-uddin [The revival of the religious sciences] (Vol. 2). Cairo, Egypt: Mustafa Al-Babi.
[18] Vanguard Newspaper. (2012). Jonathan's Birth

Control

Idea

Angers

Nigerians.

www.vanguardngr.com/health/contraception.

Acccessed on 14th July, 2013. 